\title{
A Critical Analysis of English Language Learning Guidebooks in Bangladesh
}

\author{
Shuvo Saha
}

\begin{abstract}
The English language learning guidebooks (ELLGs), among many other available materials for learning English in Bangladesh, seems to be unique as well as worthy of investigation for they claim to teach English in 30 days. In fact, they are marketed with such discourse that these guidebooks are panacea for learning English without even the assistance of any teacher, text book, or other means. One major point to be marked here is these ELLGs mainly (often solely) focus on the speaking skill and tend to claim that learning the spoken aspect of a language is equivalent to learning the language. Being moved by such anomalous discourses and facts, this qualitative study critically looks at the discourses of ELLGs available in Bangladesh to unveil their actual purpose as well as to be informed about their educational philosophy. The findings suggest that the ELLGs are utterly business oriented products (rather than ELT materials), which instrumentally promote the 'product approach based traditional form of education' (Dewey, 1938).
\end{abstract}

Keywords: English Language Learning Guidebook; English Language Teaching material; Critical Discourse Analysis; Business; Product approach oriented traditional education

\section{Introduction}

Since independence in 1971, Bangladesh is yet to have any specified language policy, which has contributed to vicious predicament as to language education, particularly English language education in the country. Due to the absence of a Language Education Policy (LEP), that can give proper guidelines on how to approach English as a foreign language (Bangla is the state language of Bangladesh constitutionally), the pedagogy appears to be in complete disarray. The country's three strata of educational system, namely Bangla medium, English medium, and Madrasa based education, teach English as a compulsory language subject (MoE, 2013). Unfortunately, yet after receiving around 12 years of English language education, from class 1 to 12 in 50 minutes session everyday, students show dismal performance in English in whatever domain they require to use the language, for say in higher education or in a competitive job market (see Banu \& Sussex, 2001). It is important to note that whereas both Bangla medium and Madrasa based education are regulated by the Ministry of Education, 
predominantly British curriculum based English medium education system is the only stratum that remains beyond any kind of monitoring on the part of the government. English medium education, therefore, throughout its history, has been found to explicitly nurture culturally incompatible versions of education through an uncritical choice of language materials, adopted from western context, and thus, has been producing culturally alienated segment of society in the form of English language learners.

The dilemma regarding an appropriate approach to learning the language has given birth to a number of chaotic issues ranging from the appropriateness of language learning materials to the testing and evaluation of the language. The chaos assumes the form of social problem when a particular section of society utilizes the discordant linguistic condition for some material profit. Those people usually target the English language learners and offer various one-stop solutions for successful language learning such as coaching centres, crash programs, locally produced - therefore claimed to be compatible and easy to use- English language learning guidebooks (ELLGs), general notebooks/guidebooks, and even methods to learn the language.

Amongst the offered means for successful foreign language learning, the local ELLGs, in this vein, are worth paying attention, since they claim to teach English in just 30 days without even the assistance of any text book, teacher, or other means. The English language learning guidebooks are different from the other category of general guidebooks in that the latter is formulated targeting students and various achievement tests they face at primary, secondary, higher secondary, and tertiary level. Test oriented such general guidebooks aim at aiding students to perform 'best' in examinations, which itself can be an independent topic for formal research, therefore, is beyond the scope of this study. Contrarily, the ELLGs target individuals from various professions and occupations such as businessmen, housewives, labourers seeking jobs abroad, and others. The English language learning guidebooks promise to aid those individuals to attain success in English language learning, which is guaranteed to bring them material benefit in the form of foreign clients or lucrative jobs. The intriguing fact about ELLGs is they solely focus on speaking amongst the four language skills, but tend to propagate that learning spoken English is equivalent to learning English language system, i.e., four skills. Thus being deceived, the users of ELLGs remain completely ignorant of three other skills of the language.

This particular research is significant because, in the first place, it can contribute to the scarce literature on ELT material evaluation from critical discourse analysis (CDA) perspective. In analyzing data, the study incorporates Fairclough's (1989) threedimensional mode of discourse analysis (used for analyzing social issues), and thus, paves the way for ELT to develop into an interdisciplinary field of study. Additionally, the research work

$134 \quad$ Journal of NELTA, Vol 18 No. 1-2, December 2013 
critically addresses the apparently innocent looking ELLGs' deceptive but hidden agenda, which remains opaque mainly due to the guidebooks' persuasive advertising and manipulative discourse. The in-depth review of literature on advertising discourse, in this vein, would assist to understand how ELLGs succeed in their act of deception and would eventually sensitize people's rational faculty. Further, the very study, in the light of John Dewey's (1938) philosophy of education " particularly "progressive education", unveils the kind of education that ELLGs cultivate. This would contribute immensely to determine the worth of ELLGs in relation to progressive nature of education. However, the present research aims at accomplishing the following objectives:

- To critically look at the cover and preface of English Language Learning Guidebooks (ELLGs) to unearth whether their real motive is to aid English language learning or something else.

- To analyze the contents of ELLGs to learn what form of education traditional or progressive ${ }^{-}$such guidebooks actually promote.

\section{Literature review}

\section{Critical discourse analysis (CDA) at a glance}

The term CDA - critical discourse analysis - refers to a process, system, or method for exposing and deconstructing the social practices, values and beliefs which may remain hidden (Al-Ali, 2006, p. 696). According to Fairclough (2001a, pp. 229-30), the starting point of CDA is social issues and problems such as globalization, social exclusion, shifts in governance, and so forth that preoccupy sociologists, political scientists, or educationists. Widdowson (2004), in this connection, is more focused to point out that the purpose of CDA is to reveal how language is used for deception, distortion, and sustenance of prejudice. Considering it an instrument, Wodak (1996, p. 16) precisely points out that exposing veiled power structures is the purpose of CDA, that plays a vital role in empowering the 'losers of the society' - the marginalized, manipulated, or excluded (Fairclough, 2001). Fairclough (2001, p. 230) argues that CDA is not only restricted to mere analysis but includes establishing connections between language and other social elements for the cause of social change. However, the principles of CDA though vary in accordance with ideology, mode of analysis, and research focus of CDA analysts, the core tenets are summarized by Fairclough and Wodak (1997, pp. 271-80) as below:

1. CDA addresses social problems

2. Power relations are discursive

3. Discourse constitutes society and culture

4. Discourse does ideological work

5. Discourse is historical

6. The link between text and society is mediated

7. Discourse analysis is interpretative and explanatory

8. Discourse is a form of social action. 


\section{Fairclough's three-dimensional model of discourse analysis}

Fairclough $(1989,1995)$ suggests that his three-dimensional approach to discourse analysis is compatible for studying sociocultural changes since the former foregrounds links between social practice and language. Additionally, the approach, he believes, can be applied to systematically investigate connections between the nature of social process and properties of language texts. In fact, the facilitative integration of micro analysis [of discourse] and of macro analysis [including analysis of language policy and planning] adds another dimension to the approach (ibid.).

The three dimensions Fairclough (1995, p. 97) views discourse and any particular instance of discursive practice through are, first, a language text- spoken or written, second, discourse practice - text production and interpretation, and third, sociocultural practice. He reveals that, in general, a piece of discourse remains embedded in socio-cultural practice at three levels - (i) the immediate situation, (ii) the wider institution or organization, and (iii) the society at large. For instance, one can read an interaction between marital partners in terms of their particular relationship between husband and wife, relationships between partners within the family as an institution, and relationship in terms of gender between male and female in the larger society. The method of discourse analysis under three-dimensional approach, however, according to Fairclough (1995, p. 97), consists of (1) description of the language text, (2) interpretation of the relationship between the discursive process and the text, and (3) explanation of the relationship between the discursive and the social process (ibid.). He, in this regard, reports that the connection between socio-cultural practice and text is established by discourse practice, which is a special feature of the approach.

\section{The advertising discourse and its impact on critical thinking}

Originated from the medieval Latin verb advertere - to direct one's attention to, the term "advertising", today, can be referred to any type of public announcement that intends to direct people's attention to the availability, qualities, or/and cost of specific commodities or services (El-daly, 2011). It is an entity that plays a significant role in the symbolic and material milieu of everyday life. Tavin (2002, p. 39) believes that advertisement can be, at a time, commodity narrative, ideological text, and site for affective investment that means location for pleasure and desire. Beasley and Danesi (2002, p. 15) characterize it by commenting that advertisement is 'becoming more and more adept at setting foot into the same subconscious regions of psychic experience that were once explored only by philosophers, artists, and religious thinkers'. Advertising, however, can be stratified into three main categories: (1) consumer advertising - directed towards general public for the promotion of some product or service, (2) trade advertising - directed towards dealers and professionals through appropriate

$136 \quad$ Journal of NELTA, Vol 18 No. 1-2, $\quad$ December 2013 
trade publications and media, and (3) public relations advertising - directed towards society through citizens or community groups or politicians for promoting some issue of social concern or political agenda (El-daly, 2011, p.25). It is to note that, among the three, the consumer advertising being of utmost relevance to the current study, the subsequent discussion in this section will be carried out in consideration to the first category of advertising.

\section{Strategies of advertising}

As regards to the strategies of advertising, Dyer (1982, p. 32) found that in the late 19th century employment of more colloquial, personal, and informal language along with certain rhetorical devices to address the customer as well as to draw attention to a product were in vogue. The ultimate goal of such practice was to create an appropriate image for a product to embed it into social consciousness. However, the three main strategies adopted today to enhance product face-value are repetition, positioning and image creation (El-daly, 2011, p. 37). Repetition is a basic marketing technique through which an advertiser can capture the attention of prospective customers by repeated appeals to buy his/her product. Positioning, on the other hand, is the placement of a product for the right kind of people (El-daly, 2011, p. 37).

Of the three advertising strategies, creating an image for product[s] has become remarkably popular now-adays. Image creation, according to Eldaly (2011, p.38), means developing a personality for any product with which a particular type of consumers can identify. The actual intention of such an advertising strategy is to categorize and set a particular target group for directly speaking to corresponding target consumers, instead of everyone, so that the former can identify themselves in the images created by advertisements for certain products. There are two means available for entrenching image associated with certain kinds of products: (i) mythologisation and (ii) logo design. Mythologisation, in the first place, is the strategy of imbuing brand names, logos, product design, and commercials intentionally with some mythological meaning. Beasley and Danesi (2002, p. 12) exemplify this by pointing out that the quest for beauty, the conquest of death are some common mythic elements which are constantly being woven into the advertising textualities of certain consumables. The second available means for establishing product image effectively, as El-daly (2011, p. 38) mentions, is logo designs. In utilizing this tool, an associative logo is formulated through particular images or words or colours to create a personality for a product. Sometimes, however, the two meansmythologisation and logo design - are simultaneously used in advertising to have deep delved impact. The McDonald's golden arches logo is an emblem of such parallel use of logo design and mythologisation. The arches in the logo reflect mythic symbolism of beckoning good people who march through those arches triumphantly into a paradise of law and order, cleanliness, friendliness, hospitality, hard work, selfdiscipline, and family values. The logo, 
thus, created consciously, implicitly hints that McDonald's is like those golden arches which pave the way for its customers to experience all such heavenly facilities in the earth (El-daly, 2011, p. 38).

\section{Critical thinking affecting mechanism of advertising discourse}

Though various strategies are adopted for accomplishing the task of advertising, more or less similar process is followed in affecting the critical minds of consumers. The general process, in which advertisements control the critical thinking of their potential consumers, includes four different stages, namely, perception, communication, learning, and persuasion (El-daly, 2011, pp. 35-37).

To begin with perception, the message of the advertisement, at this stage, is received by the viewer through various senses, then interpreted, and finally filed in his/her memory. Hence, to influence the perception about the product, target consumers' (1) attention, (2) interest, and (3) memory are aimed at. The attention is grabbed by intriguing, novel, unusual or surprising elements in the advertisements. Next, interest, which can be defined as a state of absorption in the message, is drawn by addressing a relevant message to people that they care about. Later, human memory, which is like a filing cabinet, is filled with compressed and restructured advertising messages.

At the communication stage, the second of the advertising process, particular message[s] about a product, service or an idea is transmitted to people for motivating or persuading them. In this regard, (i) clarity, (ii) completeness, and (iii) organization of the advertising text are paid special attention to. For the sake of clarity, all instances of undefined terms, unfamiliar references, poor organization, and faulty logic are taken care of. Besides, for achieving completeness and maintaining proper organization, constant reviewing is done since otherwise poor communication may take place to affect the proper execution of later stages of advertising process.

Third, at the learning stage, on the basis of effective communication, potential consumers learn about the product or service being advertised. The advertisement, this stage, moves towards getting a hold on people's critical thought process to anchor intended information or experience in the latter's memory as learned contents. This very stage is extremely essential in dragging a group of consumers towards particular product[s]. This is so because consumers, who have once consumed the product[s] are presumed to have learned something positive from the experience, and therefore, are expected to come back again. This is echoed in Caples's (1975 in El-daly, 2011, p. 37) words as he maintains that people who buy once are best proposals for buying again.

Persuasion is the final stage of achieving hold of consumer's psyche, since, at this stage a conscious attempt is made on the part of the advertisement to affect the structure of people's beliefs, opinions,

$138 \quad$ Journal of NELTA, Vol 18 No. 1-2, $\quad$ December 2013 
attitudes, convictions and motivations, so that people, in turn, act positively to purchase the consumable without thinking too much. This, in fact, can be referred to as the execution stage of marring the rational faculty of consumers to give their attitude a positive shape towards the consumable[s], which consequently would render them into uncritical consumers.

\section{Methodology}

To speak about the methodology of the research, the particular qualitative venture adheres to the principles of descriptive case study that provides fine-grain detail of the case[s] under query (see Merriam, 1988; Yin, 1984). The English language learning guidebooks (ELLGs) themselves function as data corpus required for the study. To support with qualitatively rich data, criterion sampling is adopted as a sampling procedure (Dornyei, 2007, p. 128). Five ELLGs were sampled and studied as cases over a period of eight months, starting from January 2013 to August 2013. It is to point that the sampled ELLGs were purchased by the researcher from the book markets of Banglabazar and Nilkhet at Dhaka the major publishing sites in Bangladesh for data preservation and future analysis. The data corpus, however, comprises ELLGs published in between 2004 and 2013. The collected data are analyzed using Fairclough's (1989, 1995) three-dimensional approach to discourse analysis to critically examine the discoursal patterns and practices available in the book-cover, preface, and content of ELLGs.

\section{Data analysis and findings}

For the purpose of critical analysis, the ELLGs are segmented into three core parts namely, book-cover, preface, and contents. While the analysis of bookcover and preface would work in unearthing the actual purpose of ELLGs, the analysis of contents would reveal the kind of educational philosophy ELLGs foster as well as promote.

\section{Analysis of book-cover}

To begin with, the title of ELLGs found in the book-cover is something to consider critically. The sample guidebooks the study looked at have mixed code titles, in the combination of Bangla and English, which can be translated as S@ifur's Spoken English Flash Card, Grand Spoken English, Gateway to Learn English in 30 days, Learn English in Computer method in 30 days, Learn English sitting at home in 30 days. The underlying motive for incorporating such credos as names of ELLGs is to convince their potential users to make them buy the guidebooks, emphasizing the possibility of learning English in 30 days as quite realistic.

The English language learning guidebooks in Bangladesh are, in fact, made available as readymade products as they are often marketed with expressions such as for the first time in Bangladesh, all new, all in one, new, and many others, which are usually seen in the advertisements of daily consumables, on the front cover. 
Critically speaking, such marketing expressions used for promoting ELLGs are mostly deceptive because the latest version of the guidebooks, that employ such exaggerated languages for greater sale, are found with the same contents as of their earlier versions without any sort of modification at all. In fact, with the same orientation of profit making S@ifur's Spoken English Flash Card uses its back cover for publicizing its excellence through self appraising, mixed code (of Bangla and English), rhyming note such as "Spoken nia nai r kono bhoy, S@ifur's flash card anay debay joy r joy" [No more fear with spoken English, S@ifur's flash card will bring success and joy! my translation].

The mercantile purpose of ELLGs becomes even more transparent in their presentation as they have some notable semiotic features on book-cover. The image 1 is the book-cover of a sample ELLG which shows the predominance of two most eye catchy colours - red and yellow - on both sides of its cover. Here, red being the background colour, the guidebook can easily grab and hold the attention of its potential consumers for some time at least, if not for long, while having a passing look. The alluring expressions such as "Bangladesh a ai prothom" [for the first time in Bangladesh my translation] or Flash card are placed on the front cover in two separate boxes for special attention on the part of the buyers. The font size and colour for writings in each box also vary considerably.

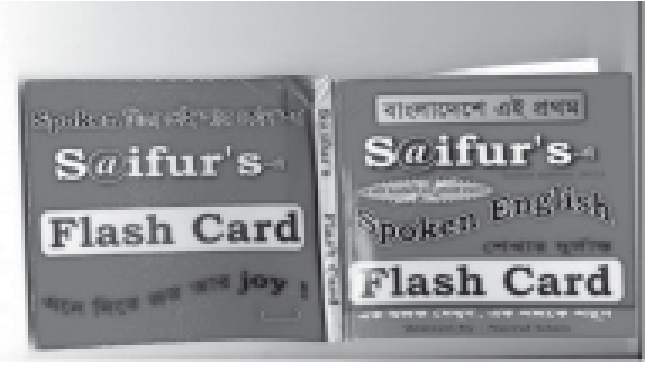

Image 1: Book-cover of S@ifur's Spoken English Flash Card

As part of a further image building strategy, the particular noun S@ifur's in the title functions as the logo for the guidebook and the logo is widely used for the advertising of this very ELLG. It is notable that the logo has the character@in it which, though, originally found in people's email addresses, is strategically used by the guidebook to entrench its association with computer. The guidebook here, through using such computer related characters, actually intersperses the logo of the product with the concept of mythologisation - the other tool for product image creation alongside the logo design (El-day, 2011). In this case, mythologisation is operationalised in the sense that there is a myth persistent in this region regarding computer that whatever material entity has some sort of association with computer, irrespective of the nature of link, must be good in quality since computer is supposed to be more efficient and qualified than humans. Therefore, the process of connecting product with computer would obstruct rationalisation among the target customers. The particular guidebook, by using the character @ in its logo S@ifur's which is passively related to computer though, attempts to popularise the 
discourse that S@ifur's ELLG ensures computer like quality in learning English. It is, however, important to take stock of the fact that for attracting people to purchase guidebooks by gaining their trust, thus to increase the sale, ELLGs such as Gateway to Learn English in 30 Days are marketed with hologram sticking on the front cover of the books claiming the authenticity of the materials.

Those ELLGs that may appear rather dependable, on the basis of plain presentation pattern at least, for instance Grand Spoken English, employ a different strategy in their cover presentation. As can be seen in image 2, the Grand Spoken English has made a concise list of all the items covered by the book and has enlisted them on the front cover. The strategy, in normal sense, may appear sane and innocent, but actually is corrupt. In adopting such approach, the particular guidebook enlists many inappropriate,

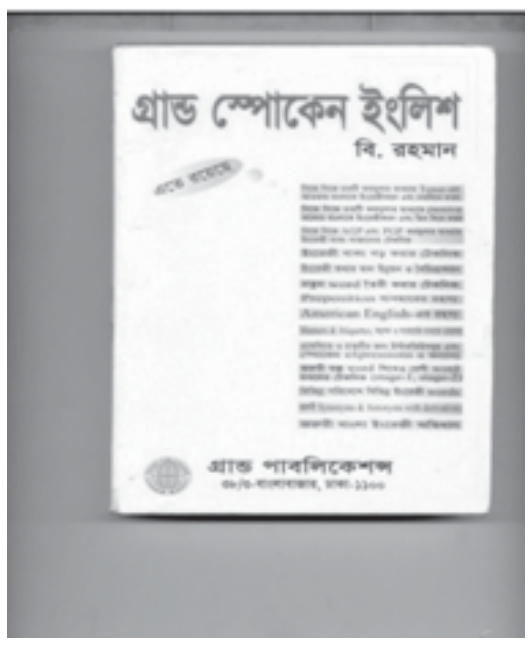

Image 2: Book-cover of Grand Spoken English unnecessary and questionable items such as, structured interviews for job in embassies and in corporate sector, or abridged dictionary from Bangla to English [the reasons why I term such items negatively are analysed in detail in the content analysis section], to make the list look rich and consequently to create a sound impression about the book. Thus, the guidebook competes with other ELLGs in selling business, ultimately deceiving the users by claiming to provide them all in one.

\section{Preface analysis}

The preface of English language learning guidebooks, in general, acts to promote the sale of the books. No single preface of the examined ELLGs mentions issues related to methodology or syllabus to be followed. Instead, the preface is used to implicitly highlight three selling points of the guidebooks in general, namely (i) short-cut means for learning English, (ii) smart teacher of situational English, and (iii) dependable source of rules for translation. These points are promoted to increase the ELLGs' intrinsic value, which consequently is supposed to contribute to an increased sale.

The first selling point short-cut means for learning English is the most frequently found one in the preface of most of the ELLGs. Most of them proudly claim to aid the learning of English in a stipulated amount of time30 days - in the "easiest and short-cut possible way". The prefaces emphasize that learning English becomes easier only when one follows the ELLG guided short-cut strategies. Gateway to Learn 
English in 30 Days, as an example, reiterates in its preface that it is the only book in the market that leads the shortest and easiest way to learn English through a list of vocabularies and translated sentences (from Bangla to English). The preface cunningly avoids mentioning exactly how the suggested contents would function to help one learn English in only 30 days. Although the prefaces reinforce the possibility of learning English within such stipulated amount of time, they do not provide any specific guideline on how long a user should work on individual lessons or topics of study to successfully accomplish the target of learning the language in 30 days. To further deceive people the prefaces of ELLGs proclaim that the corresponding guidebooks are specially adapted for short-cut learning while going to office, doing household/official chores, or even while gossiping. In this connection some prefaces, for instance the one of Learn English in Computer method in 30 days, contain credo like "Ak jholok dekhun, ak poloka porun" [Have a bird's eye view of the contents and learn within blink of eyes my translation].

Few ELLGs ask for credit in their preface for providing situational linguistic input. They, indeed, glorify their situational English based approach by asserting that one can tackle any kind of situation in English by simply studying the ELLGs. Targeting students, businessmen, various professionals, and housewives, Grand Spoken English's preface, for instance, highlights that such categories of people, particularly those who cannot speak English at all, still have the chance to impress respectively their teachers, clients, bosses, and guests by occasionally adhering to situation based English. The preface further demands that the situational dialogues and interviews (to be analysed elaborately in the content analysis section below), documented in the corresponding ELLGs, are bound to meet every type of learner's need. In this manner, the preface, to validate corresponding ELLGs' situational language contents, deliberately promotes situation based English which in turn is presumed to result in profit maximisation through an increased sale.

The third selling point, which is mainly found in prefaces of those ELLGs that claim to focus on multiple items of language on all in one basis, deals with the rules for translation of Bangla utterances into English to aid speaking. Grand Spoken English, for instance, which claims to cover 14 language items in a single edition, declares through its preface to provide its users with a 'unique' set of formulae for the task of translation. Intriguingly, to market such translation formulae, the particular category of guidebooks, in their preface, explicitly promote translation as well as encourage considering it an effective means for learning English. The discourse sounds as if the only way of strengthening the foundation in English is translation and learners need the 'ingenious' / 'learner friendly' rules of ELLGs to excel in translating. ELLGs, in this manner, are patronizing Grammar Translation Method (GTM) over other such methods as Task Based Learning (TBL) or Post method, mainly for the cause of business. 


\section{Content analysis}

The contents of ELLGs, in general, can be categorized into morphological, syntactic, and discourse level contents which are usually found as packages in the guidebooks. A package can either contain any two categories of contents as pair (i.e. morphological and syntactic contents as a pair or syntactic and discourse level contents as a pair or discourse level and morphological contents as a pair) or all the three content categories together. For instance, Learn English in 30 days sitting at home and S@ifur's Spoken English Flash Card offer the paired package of morphological and syntactic contents, whereas, Grand Spoken English's package comprises all the three categories of contents morphological, syntactic, and discourse level contents. It is important to take stock of the fact that ELLGs that offer all the three content categories as package tend to cost more than the ones that offer paired packages.

\section{Morphological contents}

The ELLG contents that can be classified under morphological category generally contain items such as English vocabularies with their synonyms and antonyms, Bangla meaning of English words, strong and weak verbs, tense wise conjugated verb forms, comparison between British and American vocabulary, and examples of a few parts of speech, e.g. of noun, pronoun, preposition, adjective, and adverb. Notably, all these morphological contents in ELLGs exist discretely, detached from context. They are presented in the form of list with each word's pronunciation pattern, transcribed through Bangla alphabets, alongside the word's equivalent Bangla meaning. The listing suggests that the particular morphological items enlisted in the guidebook, if exhaustively memorised, are sufficient to learn English.

\section{Syntactic contents}

ELLGs' syntactic components include mainly three types of language contents. First, the grammatical item tense is focused on in a rule-governed manner which is claimed by all the ELLGs to be unique. The presentation of the item can be considered unique in the sense that typical structures of tense such as subject+am/is/are+main verb+ ing, subject+shall/will+main verb base form etc. are not used while introducing learners with tense classifications like present continuous or future indefinite. Rather, a mixture of translating and recognizing the main verb ending in individual Bangla utterance happen to be the key in introducing students with various forms of tense. As an example, to acquaint learners with the tense of the sentence she/he will come, the statement is first translated into Bangla shay aashbay. The main verb ending bay of the Bangla translation is then identified as future indefinite marker, so to identify the actual English sentence to be in future 
indefinite tense. That means, students thereafter are to categorize any English utterance, with main verb ending bay after translating into Bangla, under future indefinite tense category. However, ELLG users are to memorise various other listed Bangla verb endings that symbolise certain tense types. To speak the truth, such "unique" approach to tense teaching clearly requires learners to engage in the tedious task of memorisation and translation.

Second, to acquaint ELLG users with the functional aspect of interrogative and imperative sentences, some discrete examples of both sentence types are enlisted along with their Bangla translation. Learners need to memorise both the English sentences and the corresponding translations which, according to ELLGs, would aid the former in real life to perform the functions of questioning, ordering, proposing, requesting, and so forth. Actually, such isolated listing of some selected interrogative and imperative sentences does nothing but reinforces the role of memory in learning.

Third, a number of decontextualised sentences and phrases are listed and taught as ornamental expressions. Interestingly, different guidebooks label this very syntactic content type with varying titles such as 'manners', 'etiquettes', and 'wise words' (see Table 1 ), the purpose of which is obviously to make individual ELLGs look unique in terms of content; but when the alienated sentences and phrases are critically looked at, they reflect dissonance with the literal meaning of titles 'manners', 'etiquettes', and 'wise words' under which the former is enlisted. Table 1 illustrates this issue of dissonance as it documents some of the sentences and phrases that are covered by ELLGs as ornamental expressions, manners, etiquettes, and wise words.

Table 1: Sample discrete sentences/ phrases being covered as manners/ etiquettes/wise words

\begin{tabular}{|c|c|c|}
\hline Name of ELLG & Sample sentences/Phrases & Covered as \\
\hline \multirow{4}{*}{$\begin{array}{l}\text { Learn English in } \\
30 \text { days }\end{array}$} & Nothing special. & \multirow{4}{*}{ Manners } \\
\hline & Who on earth dif this? & \\
\hline & Let me digress. & \\
\hline & It's tougher than tough. & \\
\hline \multirow{4}{*}{$\begin{array}{l}\text { Grand Spoken } \\
\text { English }\end{array}$} & Hang it. & \multirow{4}{*}{ Wise words } \\
\hline & Oh shit! & \\
\hline & I've fishes to fry. & \\
\hline & I'm leaving for America. & \\
\hline \multirow{4}{*}{$\begin{array}{c}\text { S@ifur's Spoken } \\
\text { English Flash } \\
\text { Card }\end{array}$} & Who the hell are you? & \multirow{4}{*}{$\begin{array}{l}\text { Ornamental } \\
\text { expressions }\end{array}$} \\
\hline & Be heped with the pencil. & \\
\hline & Take it as slight. & \\
\hline & His hair is falling off. & \\
\hline \multirow{4}{*}{$\begin{array}{l}\text { Learn English in } \\
\text { Computer methoo } \\
\text { in } 30 \text { days }\end{array}$} & $\begin{array}{l}\text { Time seems to hang heav } \\
\text { on my hands. }\end{array}$ & \multirow{4}{*}{ Etiquettes } \\
\hline & I am getting drenched. & \\
\hline & I am getting sweated. & \\
\hline & I have caught a cold. & \\
\hline
\end{tabular}

It is evident from the table that what ELLGs claim to teach as manners, ornamental expressions, etiquettes, or wise words, by no means can be counted as so. Categorisation and teaching of sentences such as "His hair is falling off" as ornamental expression or "It's tougher than tough" as manners convey the message that ELLGs as language learning materials are extremely poor in quality. The real aim 
of ELLGs is not to aid language learning but to transform educational materials into consumable products for commercial gain.

\section{Discourse level contents}

Discoursal content, which includes situational dialogues and interviews, is the least available one amongst the three broad categories of ELLG contents as very few guidebooks, such as Grand Spoken English, include discourse level contents in their packages. Nevertheless, structured interviews and dialogues, like other contents of ELLGs, are accompanied by their Bangla translation. Mainly corporate job interviews and interviews at embassy contexts are found in the interview section while the available dialogues generally tend to be between a salesperson and a buyer, between friends, between an employer and an employee, and between a parent and a teacher. The motive of such discourse level contents is to prepare learners to handle real life contexts through the ELLG documented dialogues and interviews. Although the very intention may sound lofty, in actuality, because of the small number of dialogues and interviews, which by no margin are representative of diverse real life contexts, the purpose is far away from practicality. There is every possibility for an ELLG user to encounter diverse new situations in actual life, apart from the ones she/he is acquainted with through the ELLGs. The discourse level contents of ELLGs, thus, completely fail to address the very fundamental issue of pragmatics.

\section{Discussion}

So far as the findings of the study suggest, the English language learning guidebooks' actual intention appears to be doing business; and this addresses the very first objective of the research, set earlier in the introduction. The mercantile motive of ELLGs becomes evident on book-cover and in preface that typify the discourse pattern and semiotic features of advertising. It is observable, in the first place, that the expressions used in branding of consumable goods, for say toothpaste, water purifier, or technological gazettes, are commonplace in the discourse choices of ELLGs. The ultimate aim of such a discoursal approach is to convince the target group as to the charismatic power of ELLGs, in consequence, to make them buy those materials. Secondly, the semiotic features of such guidebooks play a similar role to present ELLGs as one of a kind readymade product which can provide one-stop access to the language learning. For the purpose of attaining the identity of consumable products, the guidebooks resort to consumer advertising (EL-daly, 2011). Such kind of advertising is strategically done by creating associative images for ELLGs, instrumented by corresponding pictures, eye catchy colour, noteworthy font size, holograms and so forth means. These, at the end, leave commoners with marred rationality to hypnotise them to purchase the ELLGs. Truly speaking, such a semiotic strategy adopted by ELLGS is deceitful because those semiotic traits are all extralinguistic which have hardly any nexus with the essence of language learning. Thus, the discourse and semiotic features of ELLGs are clearly testament to their commercial objectives. 
Additionally, the packaged system of ELLGs' contents (evident from content analysis) reiterates the fact that such guidebooks, in every possible way, mean nothing but business, as the number of contents in an ELLG determines the price of that guidebook.

To reflect on the second objective of the study, it can unarguably be claimed that ELLGs are patrons of traditional form of education (Dewey, 1938). The way the language contents of ELLGs morphological, syntactic, and discourse level contents are presented and taught, offers one the impression of typical grammar books following Grammar Translation Method (GTM). The three categories of contents exist in isolated and decontextualized manner which are to be memorised by ELLG users. It signifies how far removed ELLGs are from the principles of 'progressive education' (ibid.).

\section{Implications}

The locally published English language learning guidebooks in Bangladesh commonsensically may appear a fast aiding, all in all means for learning the language; in reality, they are useful instruments to manipulate non-critical learners. The analysis of book-cover and preface suggests that ELLGs operate to deceive people for commercial gains, mainly by means of eye catchy outward make-up and/or persuading discourse. In this vein, ELLGs' attempt to create an image for themselves as readymade products, for promoting a 'product approach' (Dewey, 1938) to education, can have detrimental effects on learners as they might conceptualize that learning, broadly speaking education, is similar to using a product which can be consumed anywhere in no time to produce immediate effects.

In addition, the contents of ELLGs, which are presented in linear fashion and are taught exhaustively, barely provide learners with the opportunity of coming back to the items being covered for revision. Therefore, learners run the risk of completely forgetting what they learned initially. This particular issue can be addressed by resorting to a 'cyclical arrangement of language items' (Cunningsworth, 1984, p. 26) that enables learners to revise the already learned items. However, ELLG contents' exclusive emphasis on memorisation of discretely listed morphological and syntactic components not only patronises a product approach to learning but disregards learners by treating them as entities with empty heads to be filled up by the ELLG transmitted knowledge. Such philosophy of education, which Dewey (1938) marks as 'miseducative', stands in stark contrast with the progressive principle of education which, rather, views learning as an ongoing process and provides learners with the scope to incorporate their experiential knowledge to enrich the existing level of knowledge.

\section{Conclusion}

While the current study attempts to unveil the mercantile psyche of ELLGs and of people associated with them, it has some other pedagogic significance too. The research, complying with the progressive principles of education, encourages language learners to choose those materials that take stock of learners' previous experience in the learning process. This would not simply

$146 \quad$ Journal of NELTA, Vol 18 No. 1-2, $\quad$ December 2013 
ensure learner autonomy in learning but lead one to come out of the shackles of dependency on language learning materials. Moreover, the study forms the ground for further research on imported ELT materials in EFL setting like Bangladesh since materials from inner circle countries, such as UK and USA, may have other targets to achieve than simply disseminating language education which are, therefore, worthy of scholarly investigation.

\section{References}

Al-Ali, M. N. (2006). Religious affiliations and masculine power in Jordanian wedding invitation genre. Discourse and Society, 17(6), 691-714. DOI: 10.1177/ 0957926506068428

Banu, R. \& Sussex, R. (2001). English in Bangladesh after independence: Dynamics of policy and practice. In B. Moore's (ed.), Who's centric now? The present state of postcolonial Englishes (pp.122-47). Victoria: Oxford University Press.

Beasley, R. \& Danesi, M. (2002). Persuasive Signs. New York: Berlin.

Cunningsworth, A. (1984). Evaluating and selecting EFL teaching materials. London: Heinemann Educational Books Ltd.

Dewey, J. (1938). Experience and Education. New York: Kappa Delta Pi.

Dornyei, Z. (2007). Research Methods in Applied Linguistics. New York: Oxford University Press.

Dyer, G. (1982). Advertising as communication. London: Routledge.

El-daly, H. M. (2011, June).Towards an Understanding of the Discourse of Advertising: Review of Research with Special Reference to the Egyptian Media. African Nebula, 3, 25-47.

Fairclough, N. (1989).Language and Power. London: Longman.
Fairclough, N. (1995).Critical Discourse Analysis: The critical study of language. London: Longman.

Fairclough, N. (2001). The Discourse of new labor: Critical Discourse Analysis. In M Wetherell, S. Taylor, \& S. J. Yates (eds.), Discourse as data: A guide for analysis (pp. 229-66). London: Sage.

Fairclough, N. \& Wodak, R. (1997). Critical discourse analysis. In T. van Dijk (ed.), Discourse studies: A multidisciplinary introduction, Discourse as social interaction (Vol. 2, pp. 258-84). London: Sage.

Merriam, S. B. (1988) Case Study Research in Education. San Francisco: Jossey Bass.

Ministry of Education, The People's Republic of Bangladesh. (2013). Structure of education system. Retrieved on July 27, 2013, fromhttp://www.moedu.gov.bd/ index.php?option $=$ com_content\&task $=$ view\&id=247\&Itemid=267.

Tavin, K. (2002). Engaging Advertisements: Looking for Meaning In and Through Art Education. Visual Arts Research,28, 2(56), 38-47.

Widdowson, H. G. (2004). Text, Context, Pretext: Critical issues in Discourse Analysis. London: Blackwell.

Wodak, R. (1996). Disorders of Discourse. London: Longman.

Yin, R. K. (1984) Case Study Research: Design and Methods. Beverly Hills: Sage.

\section{About the author}

Shuvo Saha is a Graduate Teaching Assistant at East West University, Bangladesh. He presented the research paper "Jawmadar or Cleaner - Who Serves Best? Ethnolinguistic Resistance in Old Dhaka's Shankhari Community" in the $6^{\text {th }}$ BELTA International Conference, 2013. His area of reading and writing range across ELT, CDA, Minority language, Post colonial studies, Linguistic anthropology, Orientalism, and relevant interdisciplinary domains. 